\title{
DESAIN PARTISI PENYERAP NOISE BERBAHAN KOMPOSIT KAIN PERCA
}

\author{
Centaury Harjani \& Patricia P. Noviandri* \\ Program Studi Desain Produk \& Program Studi Arsitektur, \\ Fakultas Arsitektur dan Desain, Universitas Kristen Duta Wacana.
}

\begin{abstract}
ABSTRAK
Interior di dalam rumah tidak lepas dari penggunaan partisi. Partisi yang digunakan sebagai pemisah antara dua ruangan yang berbeda ini dapat dibuat dengan material daur ulang dari limbah industri, seperti kain perca. Kain perca memiliki sifat dapat menyerap bunyi. Ini adalah potensi untuk diolah menjadi produk interior berupa partisi yang dapat menyerap suara bising (noise). Partisi ini dapat berfungsi ganda, selain sebagai partisi sekat untuk memisahkan dua ruangan, sekaligus juga berfungsi sebagai peredam suara dalam mengurangi noise suatu ruang. Pembuatan kompositnya menggunakan teknik cetak tuang secara manual dengan memanfaatkan kain perca dan material gipsum sebagai perekatnya. Metode eksperimen digunakan dalam mengembangkan material komposit untuk partisi penyerap noise berbahan gipsum dan kain perca ini. Desain akan dibuat dengan konsep modular sehingga pengguna nantinya dapat merangkai sendiri partisi yang diinginkannya, dengan demikian ukuran rangkaian partisi dapat disesuaikan dengan kebutuhan ruang yang ada. Tulisan ini diharapkan dapat memberi wawasan baru mengenai pengolahan daur ulang kain perca menjadi suatu produk interior.
\end{abstract}

Kata Kunci: partisi, panel akustik, komposit, daur ulang perca, cetak tuang.

\section{PENDAHULUAN}

Perumahan-perumahan di Yogyakarta berkembang sangat pesat. Perkembangan perumahan didominasi perumahan untuk kalangan menengah dengan lahan yang terbatas. Rumah sederhana itu biasanya digunakan oleh keluarga muda yang modern dan masih berkembang. Keluarga muda umumnya masih memiliki keinginan-keinginan untuk berkembang, baik penghasilan, keturunan, dan tempat tinggal. Dengan penghasilan yang tidak berlebih mereka umumnya membeli rumah dengan ruang yang terbatas. Keterbatasan ruang ini tentunya akan ada permasalahan mengenai kebisingan. Kebisingan karena suara yang tidak dikehendaki dapat mengganggu konsentrasi ataupun kenyamanan sesorang, karena itu dibutuhkan suatu pereda kebisingan untuk meningkatkan kualitas suatu ruangan. Ada beberapa sumber kebisingan di dalam suatu ruangan, yaitu: bising interior dan bising luar outdoor (Leslie L. Doelle, 1990). Oleh sebab itu banyak pula penghuni yang memilih menggunakan partisi. Partisi merupakan salah satu penunjang interior rumah. Pemilihan partisi berdasarkan aspek fungsional dan aspek estetika. Dalam aspek fungsi, partisi adalah pembatas ruang yang fleksibel. Selama ini partisi untuk rumah tinggal hanya digunakan sebagai pembatas secara visual tetapi kebisingan/suara masih tanpa batas. Kebutuhan privasi antara ruang yang satu dengan ruang yang lain menjadi tinggi, karena itu tulisan ini akan membahas bising interior yaitu kebisingan yang berasal dari manusia maupun peralatan yang mereka gunakan. Cara mengatasi atau menanggulangi kebisingan jenis ini adalah dengan mengoptimalkan partisi/sekat pemisah suatu ruangan yang dapat menyerap sumber asal bunyi bising, dengan melakukan uji coba material akustik untuk kemudian mendesainnya menjadi partisi.

\section{PEMBAHASAN}

Noise atau kebisingan sangat subjektif bagi setiap orang. Namun demikian, ada jenis bunyi yang dianggap nois bagi kembanyakan orang yaitu bunyi keras yang muncul mendadak, bunyi keras yang muncul terus menerus dan sebagainya. Dalam nois dikenal istilah background noise. Background noise adalah bunyi disekitar kita yang muncul secara tetap dan stabil pada tingkat tertentu. Background noise yang nyaman berada pada tingkat kekerasan tidak melebihi $40 \mathrm{~dB}$. 
Dalam perambatan bising (termasuk bunyi / suara), ada 3 unsur utama yang berperan (Sutanto, 2015) yaitu:
a. sumber bising (sumber bunyi / suara)
b. media perambatan bising (media perambatan bunyi/suara)
c. penerima biasing (penerima bunyi / suara)

Terdapat 3 langkah pengontrolan bising menurut Sutanto (2015) antara lain:
a. Kontrol / Atenuasi Bising pada Sumbernya
b. Kontrol / Atenuasi Bising pada Media Rambat / Media Perantara
c. Kontrol / Atenuasi Bising pada Penerima

Dalam bidang arsitektur, yang paling berpengaruh adalah kontrol / atenuasi bising pada media rambat / media perantara. Pemutusan pada media perantara ini umumnya dilakukan secara fisik dengan cara:

a. Memisahkan peralatan/area bising dengan penerimanya dengan memanfaatkan desain arsitektur dan tata ruang bangunan maupun pengkondisian lingkungan serta perancangan tapak.

b. Membangun isolator dari sumber bunyi (dari area bising) ke penerimanya (ke area yang memerlukan ketenangan)

c. Menerapkan lapisan material pengabsorbsi suara pada pelingkup ruang dalam / area sumber suara dan atau pada ruang penerimanya.

berikut:

Leslie L. Doelle menyatakan ada beberapa tingkat bising rata-rata yang biasa seperti

Tabel 1 Tingkat Bising Rata-rata yang Biasa (Typical) (Sumber: Doelle, Leslie L, 1990)

\begin{tabular}{|c|c|}
\hline Sumber bising & Tingkat bising, dB \\
\hline Detik arloji & 20 \\
\hline Halaman tenang & 30 \\
\hline Rumah tenang pada umumnya & 42 \\
\hline Jalan pemukiman yang tenang & 48 \\
\hline Kantor bisnis pribadi & 50 \\
\hline Kantor lansekap & 53 \\
\hline Kantor besar yang konvensional & 60 \\
\hline Pembicaraan normal, $3 \mathrm{ft}(90 \mathrm{~cm})$ & 62 \\
\hline Mobil penumpang di lalu lintas kota, $20 \mathrm{ft}(6 \mathrm{~m})$ & 70 \\
\hline Pabrik tenang & 70 \\
\hline Mobil penumpang di jalan raya, $20 \mathrm{ft}(6 \mathrm{~m})$ & 76 \\
\hline Pembicaraan keras, $3 \mathrm{ft}(90 \mathrm{~cm})$ & 78 \\
\hline Pabrik yang bising & 80 \\
\hline Mesin kantor, $3 \mathrm{ft}(90 \mathrm{~cm})$ & 80 \\
\hline Ruang teletype surat kabar & 80 \\
\hline Motor tempel 10-hp, $50 \mathrm{ft}$ (15 m) & 88 \\
\hline Lalu lintas kota pada jam sibuk, 10 ft (3m) & 90 \\
\hline Jet besar lepas landas, $3.300 \mathrm{ft}(1.000 \mathrm{~m})$ & 90 \\
\hline Motor sport atau truck, $3 \mathrm{ft}(90 \mathrm{~cm})$ & 94 \\
\hline Bedil riveting, $3 \mathrm{ft}(90 \mathrm{~cm})$ & 100 \\
\hline Mesin potong rumput berdaya, $10 \mathrm{ft}(3 \mathrm{~m})$ & 105 \\
\hline Band musik rock & 113 \\
\hline Jet besar lepas landas, $500 \mathrm{ft}(150 \mathrm{~m})$ & 115 \\
\hline Sirene 50-hp, $100 \mathrm{ft}(30 \mathrm{~m})$ & 138 \\
\hline Rocket ruang angkasa & 175 \\
\hline
\end{tabular}


Christina E. Mediastika, mengatakan bahwa kebisingan dalam ruangan tertutup disebabkan juga oleh bunyi pantulan sumber asal suara bising, untuk meredakn kebisingan jenis ini dalam suatu ruangan dapat memanfaatkan penghalang untuk memantulkan suara bising. Penghalang perlu diatur sedemikian rupa karena bising tersebut dapat teredam oleh udara yang ada.

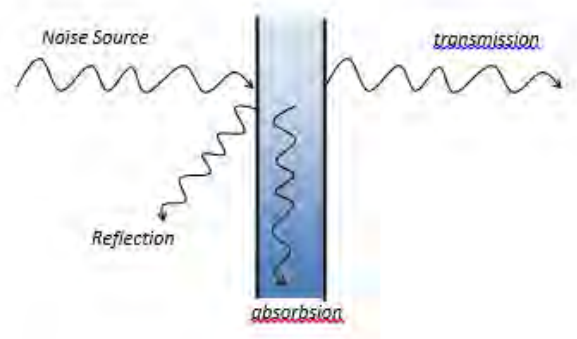

Gambar 1 Peristiwa terjadinya refleksi, absorbsi, dan transmisi suara pada suatu benda.

(Sumber: Sutanto, 2015)

Bahan bangunan yang lunak, lembek, dan berpori akan menyerap sebagian besar gelombang bunyi yang menumbuknya. Selain bahan bangunan, isi ruangan seperti tirai, karpet, tempat duduk dengan lapisan lunak, tempat tidur dengan kasur, manusia serta udara dalam ruangan juga termasuk golongan bahan penyerap bunyi.

Efisiensi penyerapan bunyi suatu bahan pada frekuensi tertentu dinyatakan oleh koefisien penyerapan bunyi. Koefisien penyerapan bunyi datang yang diserap atau tidak dipantulkan oleh permukaan. Koefisien ini dinyatakan dalam huruf Yunani $\alpha$. Nilai $\alpha$ antara 0 dan 1 didasarkan pada presentase penyerapan bunyi oleh bahan pada frekuensi tertentu. Frekuensi standar yang diperoleh $125,250,500,1000,2000$, dan $4000 \mathrm{~Hz}$.

Tabel 2 Koefisien Absorbsi Beberapa Material Bangunan

\begin{tabular}{|c|c|}
\hline Material Bangunan & $\begin{array}{c}\text { Koefisien Absorbsi pada } \\
\text { Frekuensi } 500 \mathrm{~Hz}^{*}\end{array}$ \\
\hline \multicolumn{2}{|l|}{ Lantai : } \\
\hline Semen & 0.015 \\
\hline Semen dilapis keramik & 0.01 \\
\hline Semen dilapis karpet tipis & 0.05 \\
\hline Semen dilapis karpet tebal & 0.14 \\
\hline Semen dilapis kayu & 0.10 \\
\hline \multicolumn{2}{|l|}{ Dinding } \\
\hline Batu bata diplester halus & 0.02 \\
\hline Batu bata diplester kasar & 0.01 \\
\hline Batu bata diekspose & 0.06 \\
\hline Papan kayu & 0.10 \\
\hline Kolom beton di cat & 0.04 \\
\hline Kolom beton tidak dicat & 0.06 \\
\hline Tirai kain tipis / sedang / tebal & $0.11 / 0.49 / 0.55$ \\
\hline Kaca halus & 0.01 \\
\hline Kaca kasar / buram & 0.04 \\
\hline \multicolumn{2}{|l|}{ Plafon } \\
\hline Beton dak & 0.015 \\
\hline Eternit & 0.17 \\
\hline Gipsum & 0.05 \\
\hline Aluminium, Furnitur, dll & 0.01 \\
\hline Kursi Kain & 0.60 \\
\hline Kursi plastic & 0.01 \\
\hline Udara & $0.007 * *$ \\
\hline Manusia & 0.46 \\
\hline
\end{tabular}


Material Akustik pada umumnya merupakan material yang berfungsi menyerap bunyi (material yang bersifat absorbtif). Mayoritas berupa material yang bobotnya ringan dan memiliki porositas tinggi yang secara factual umumnya juga dapat meneruskan (mentransmisikan) suara. Bahan insulasi bunyi yang efektif akan menjadi suatu bahan yang berfungsi sebagai peredam terhadap tranmisi bunyi dari satu sisi ke sisi yang lain dari ruangan. Salah satu material akustik adalah karpet, anyaman kain, dan bahan sejenisnya.

\section{PROSES UJI COBA PEMBUATAN PANEL}

Sekat/Partisi yang dibuat akan difungsikan sebagai penghalang bunyi yang diharapkan dapat memantulkan maupun menyerap sumber bunyi bising yang ada. Adapun pembuatan panel ini menggunakan material daur ulang dari kain perca dan menjadikannya komposit dengan campuran material gipsum.

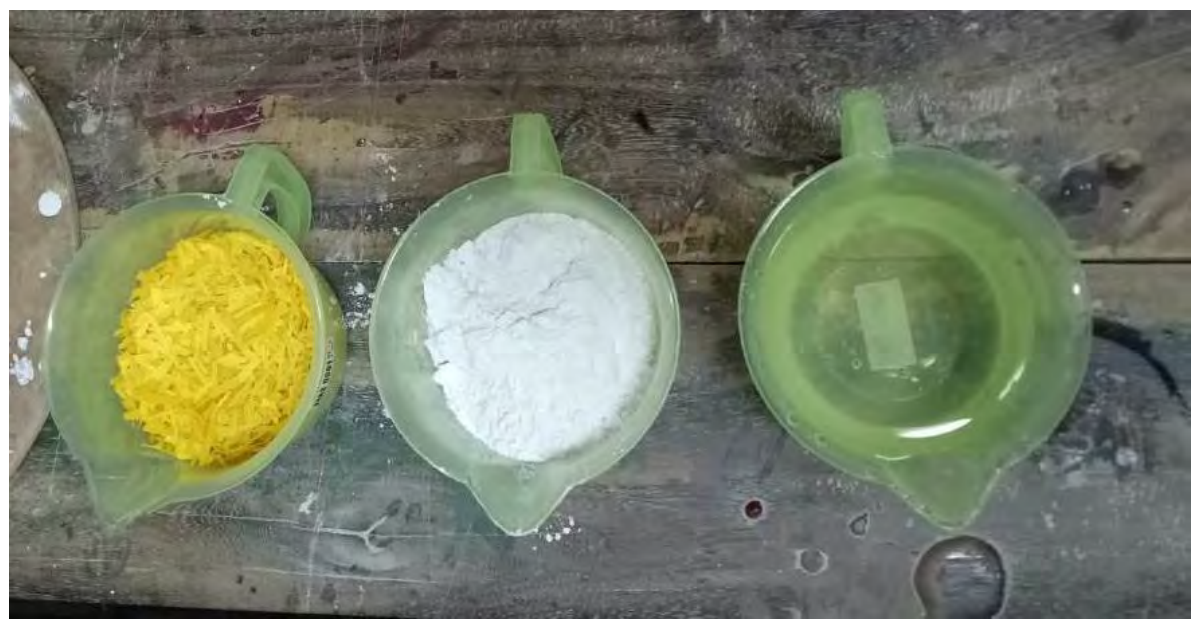

Gambar 2 Bahan-bahan Campuran Komposit (kain - gipsum - air)

(Sumber: Dokumentasi Centaury, 2018)

Kain yang digunakan dalam membuat material penyerap bising (noise) terdiri dari tiga ukuran yang berbeda dan dua jenis yang berbeda, yaitu perca dari material denim dan drill, berikut adalah gambarnya:

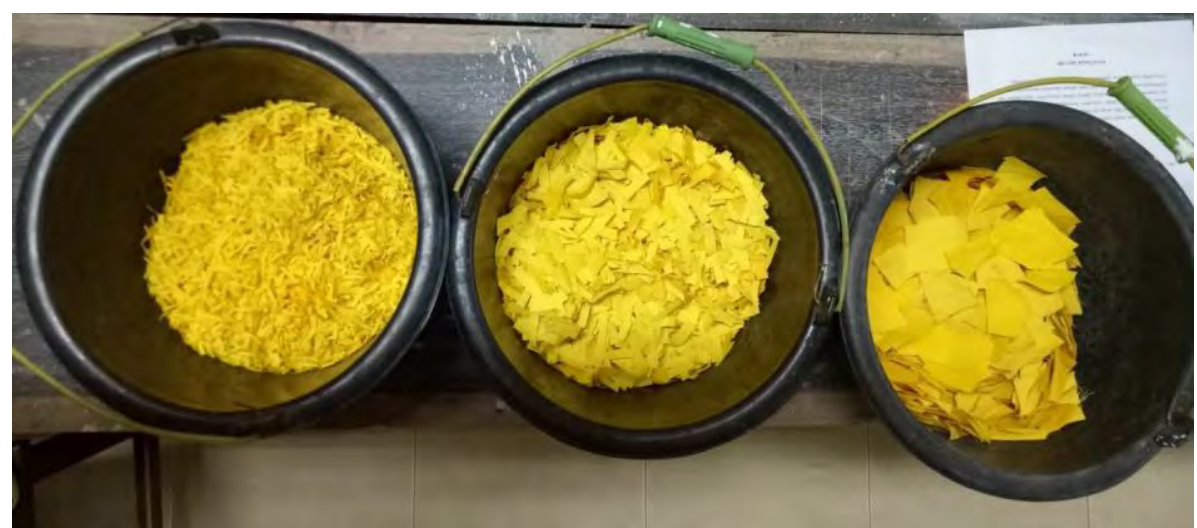

Gambar 3 Material Drill (Ukuran halus - sedang - besar) (Sumber: Dokumentasi Centaury, 2018) 


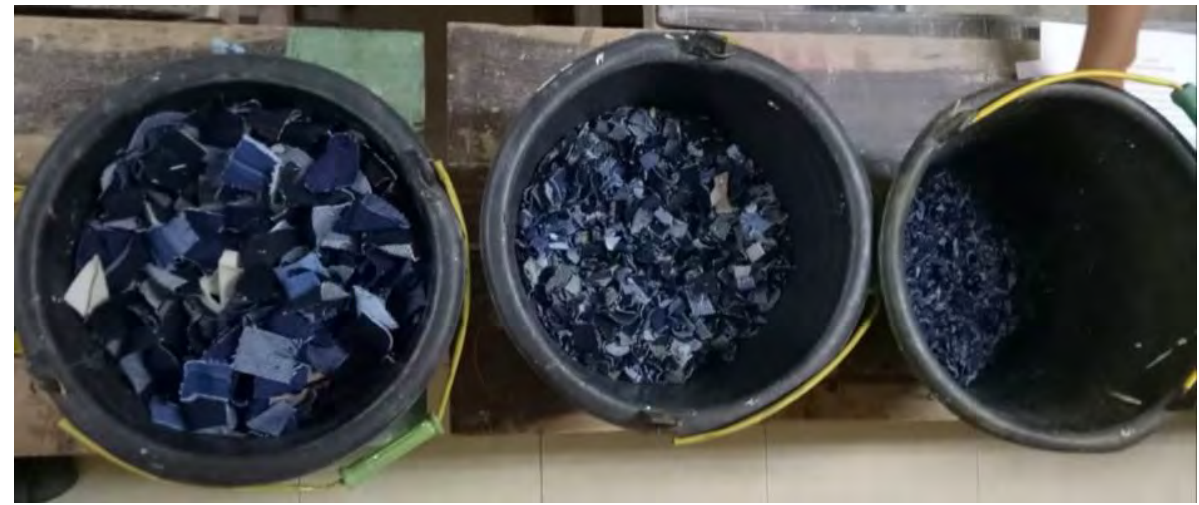

Gambar 4 Material Denim (Ukuran halus - sedang - besar) (Sumber: Dokumentasi Centaury, 2018)

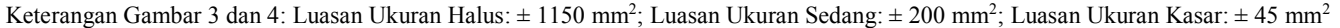

Bahan-bahan tersebut akan dicetak menjadi panel berukuran 20x20x1cm, seperti di bawah ini:

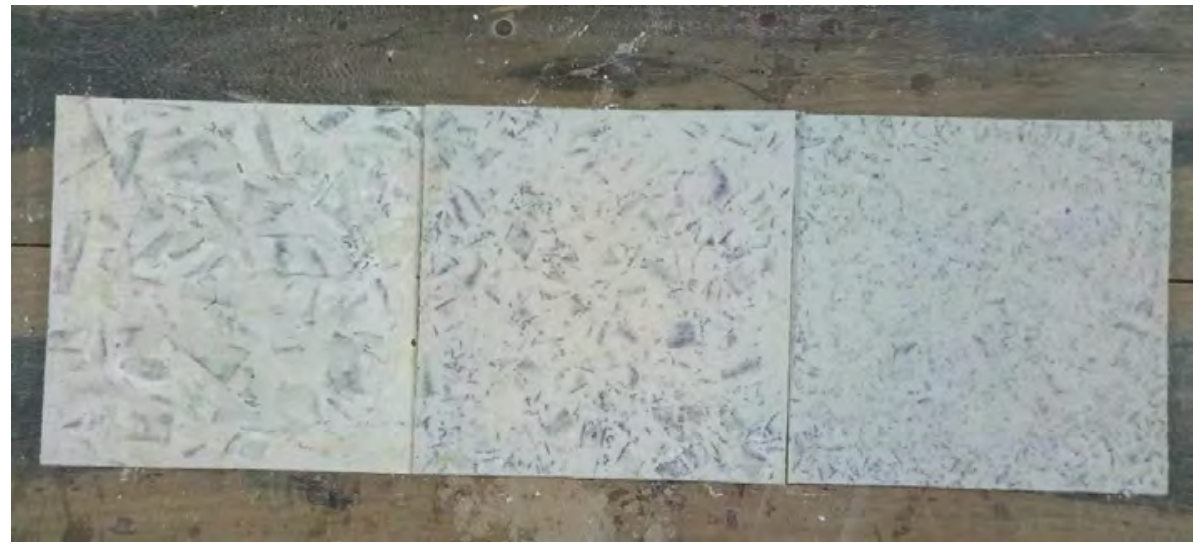

Gambar 5 Komposit Gipsum dan Denim (Kasar - Sedang - Halus) (Sumber: Dokumentasi Centaury, 2018)

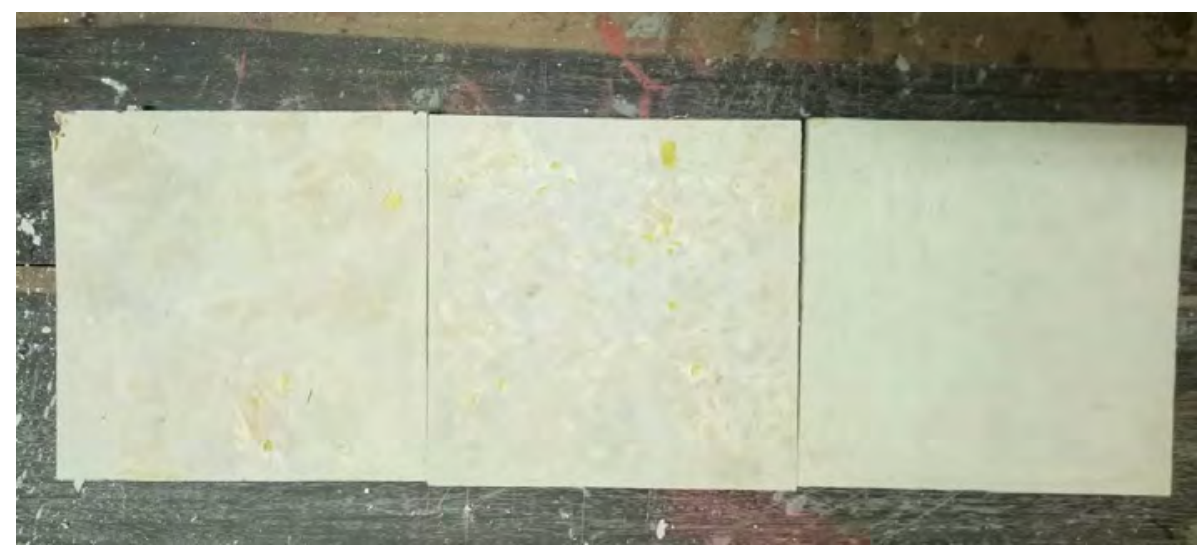

Gambar 6 Komposit Gipsum dan Drill (Kasar - Sedang - Halus)

(Sumber: Dokumentasi Centaury, 2018) 


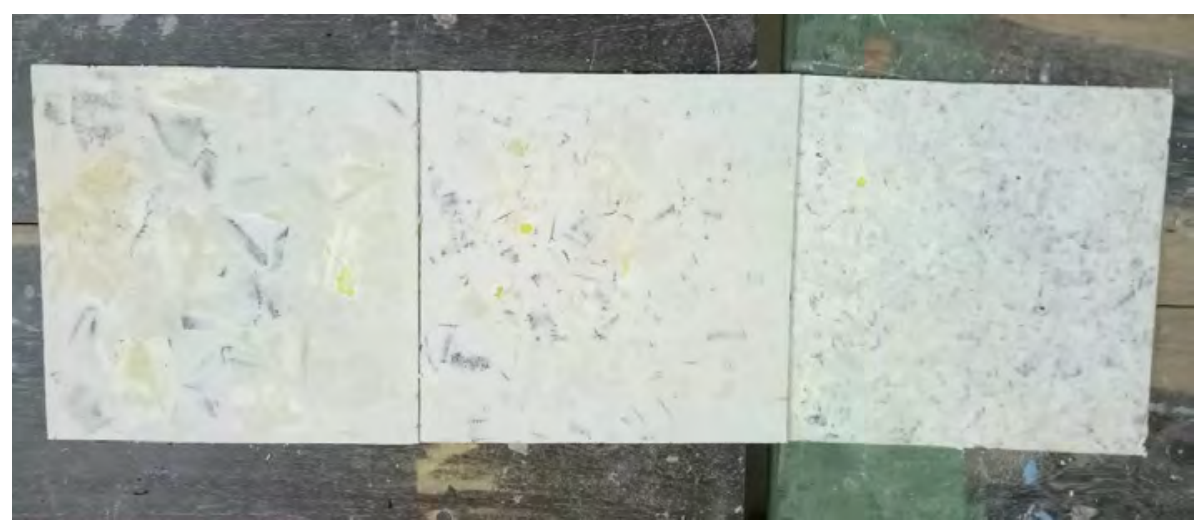

Gambar 7 Komposit Gipsum, Denim, dan Drill (Kasar - Sedang - Halus) (Sumber: Dokumentasi Centaury, 2018)

\title{
PENGUJIAN DAYA SERAP SUARA PADA PANEL AKUSTIK
}

Panel-panel yang ada kemudian diuji noise reduction dengan membandingkan frekuensi masuk dan frekuensi keluar dari pengukuran SPL yang ada, sesuai diagram dibawah ini:

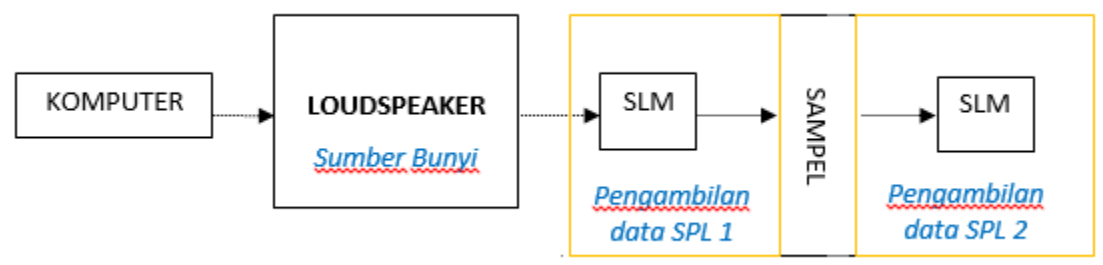

Noise reduction dihitung menggunakan rumus berikut ini: NR = SPL1 - SPL2

\author{
Keterangan: \\ $\mathrm{NR}=$ Noise Reduction $(\mathrm{dB})$ \\ SPL1 $=$ SPL sumber bunyi $(\mathrm{dB})$ \\ SPL2 = SPL penerima bunyi $(\mathrm{dB})$ \\ (Sumber: Egan, 1972)
}

\section{HASIL UJI COBA PANEL}

Adapun berikut ini adalah hasil noise reduction yang diperoleh:

Tabel 3 Hasil Pengukuran Noise Reduction

\begin{tabular}{|l|c|c|c|}
\hline \multirow{2}{*}{\multicolumn{1}{c|}{ MATERIAL }} & \multicolumn{3}{|c|}{ FREKUENSI 125 Hz } \\
\cline { 2 - 4 } & SPL 1 & SPL2 & NR \\
\hline Gipsum & 69.8 & 64.7 & 5.1 \\
\hline Gipsum+Denim Halus & 67.7 & 61.3 & 6.4 \\
\hline Gipsum+Denim Sedang & 68.4 & 63.1 & 5.3 \\
\hline Gipsum+Denim Kasar & 68.2 & 59.2 & 9 \\
\hline Gipsum+Drill Halus & 69.1 & 61.9 & 7.2 \\
\hline Gipsum+Drill Sedang & 69.0 & 63.3 & 5.7 \\
\hline Gipsum+Drill Kasar & 68.4 & 61.7 & 6.7 \\
\hline Gipsum+Denim+Drill Halus & 67.9 & 64.6 & 3.3 \\
\hline Gipsum+Denim+Drill Sedang & 69.9 & 63.3 & 6.3 \\
\hline Gipsum+Denim+Drill Kasar & 67.8 & 61.6 & 6.2 \\
\hline
\end{tabular}


Berdasarkan table di atas dapat disimpulkan bahwa memberikan campuran material kain pada gipsum, menghasilkan material komposit dengan nilai noise reduction yang lebih baik daripada material gipsum. Komposit yang dihasilkan juga memiliki tekstur yang estetis, dari hasil ini dikembangkanlah suatu desain partisi yang sekaligus berfungsi sebagai noise reduction.

\section{DESAIN PARTISI}

Aspek-aspek yang dipertimbangkan dalam mendesain partisi adalah sistem modular, dapat dibongkar pasang, adapun desain yang dirancang sebagi berikut:
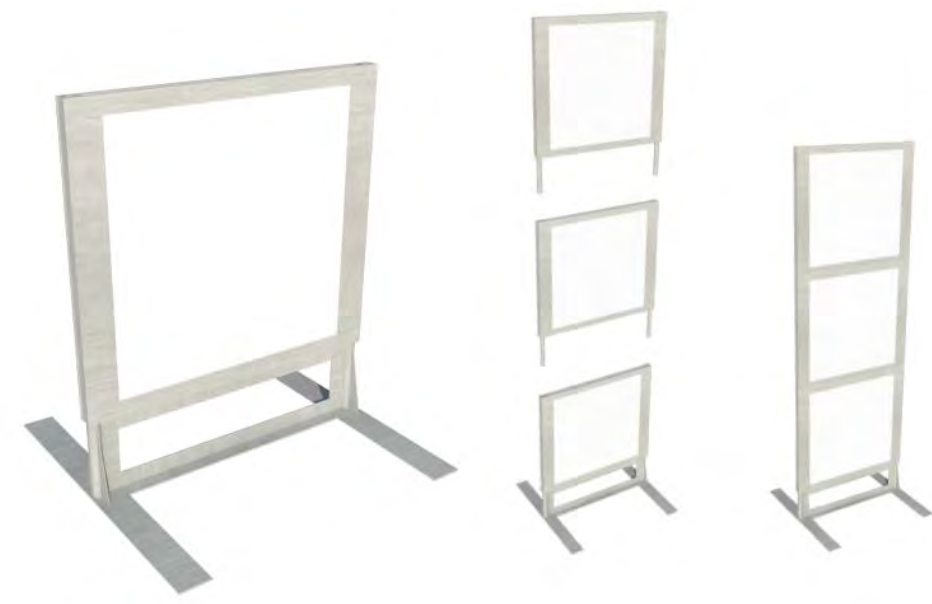

Gambar 8. Modul Panel

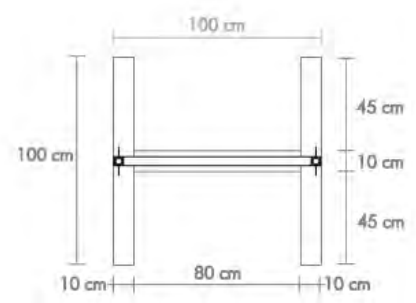

$\frac{\text { Tompak atos }}{\text { itoin } 1: 20}$

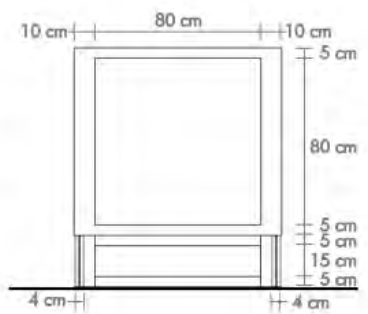

$\frac{\text { Tompak Depan }}{\text { inlo } 120}$

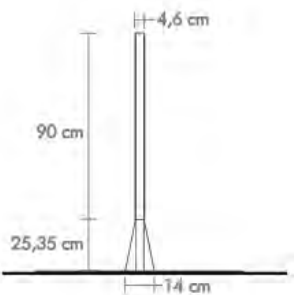

$\frac{\text { Tampak Samping }}{\operatorname{sinh1.20}}$

Gambar 9 Gambar Tampak dengan Ukuran 


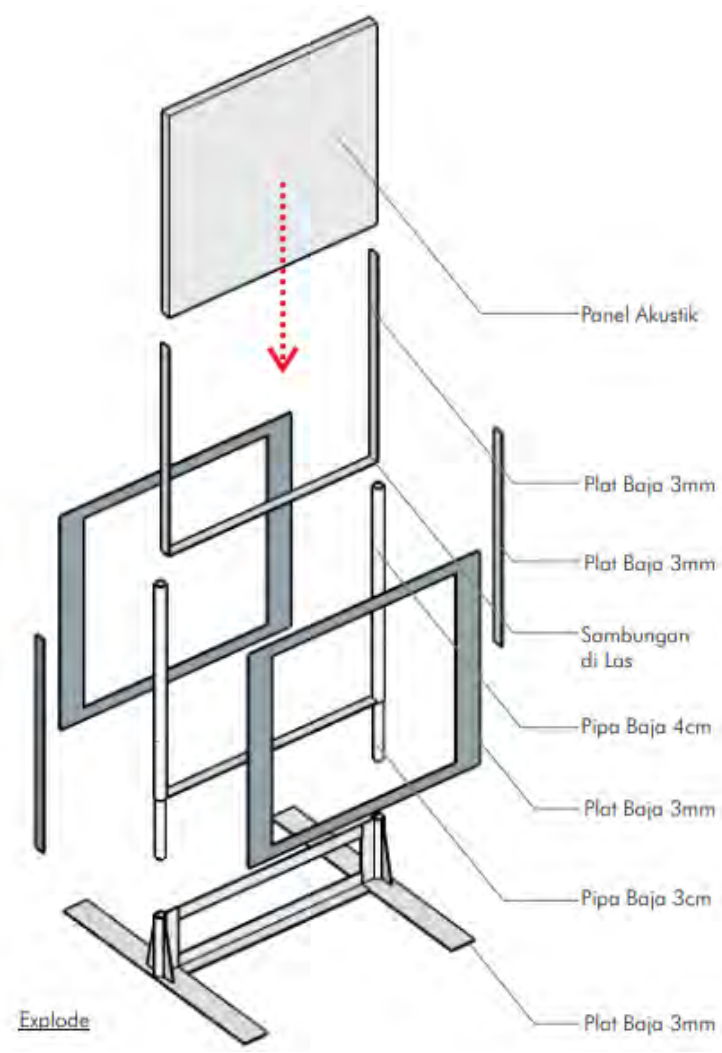

Gambar 10 Gambar Detail

\section{DAFTAR PUSTAKA}

Doelle, Leslie L. dan Lea Prasetio. 1990. Akustik Lingkungan. Jakarta: Penerbit Erlangga

Egan, M.D. 1972. Concepts In Architectural Acoustics. New York: McGraw-Hill Inc.

Mediastika, Christina E. 2005. Akustika Bangunan Prinsip-prinsip dan Penerapannya di Indonesia. Jakarta: Penerbit Erlangga

Sutanto, Handoko. 2015. Prinsip-prinsip Akustik dalam Arsitektur. Yogyakarta: Kanisius. 